Hydrol. Earth Syst. Sci., 17, 3095-3110, 2013

www.hydrol-earth-syst-sci.net/17/3095/2013/

doi:10.5194/hess-17-3095-2013

(C) Author(s) 2013. CC Attribution 3.0 License.

\title{
A study on WRF radar data assimilation for hydrological rainfall prediction
}

\author{
J. Liu ${ }^{1,2}$, M. Bray ${ }^{3}$, and D. Han ${ }^{2}$ \\ ${ }^{1}$ State Key Laboratory of Simulation and Regulation of Water Cycle in River Basin, China Institute of Water Resources and \\ Hydropower Research, Beijing 100038, China \\ ${ }^{2}$ Water and Environmental Management Research Centre, Department of Civil Engineering, University of Bristol, \\ Bristol BS8 1TR, UK \\ ${ }^{3}$ Hydro-environmental Research Centre, School of Engineering, Cardiff University, Cardiff CF24 ODE, UK
}

Correspondence to: J. Liu (jia.liu@iwhr.com)

Received: 26 July 2012 - Published in Hydrol. Earth Syst. Sci. Discuss.: 11 September 2012

Revised: 30 May 2013 - Accepted: 29 June 2013 - Published: 2 August 2013

\begin{abstract}
Mesoscale numerical weather prediction (NWP) models are gaining more attention in providing highresolution rainfall forecasts at the catchment scale for realtime flood forecasting. The model accuracy is however negatively affected by the "spin-up" effect and errors in the initial and lateral boundary conditions. Synoptic studies in the meteorological area have shown that the assimilation of operational observations, especially the weather radar data, can improve the reliability of the rainfall forecasts from the NWP models. This study aims at investigating the potential of radar data assimilation in improving the NWP rainfall forecasts that have direct benefits for hydrological applications. The Weather Research and Forecasting (WRF) model is adopted to generate $10 \mathrm{~km}$ rainfall forecasts for a $24 \mathrm{~h}$ storm event in the Brue catchment $\left(135.2 \mathrm{~km}^{2}\right)$ located in southwest England. Radar reflectivity from the lowest scan elevation of a C-band weather radar is assimilated by using the three-dimensional variational (3D-Var) dataassimilation technique. Considering the unsatisfactory quality of radar data compared to the rain gauge observations, the radar data are assimilated in both the original form and an improved form based on a real-time correction ratio developed according to the rain gauge observations. Traditional meteorological observations including the surface and upper-air measurements of pressure, temperature, humidity and wind speed are also assimilated as a bench mark to better evaluate and test the potential of radar data assimilation. Four modes of data assimilation are thus carried out on different types/combinations of observations: (1) traditional
\end{abstract}

meteorological data; (2) radar reflectivity; (3) corrected radar reflectivity; (4) a combination of the original reflectivity and meteorological data; and (5) a combination of the corrected reflectivity and meteorological data. The WRF rainfall forecasts before and after different modes of data assimilation are evaluated by examining the rainfall temporal variations and total amounts which have direct impacts on rainfall-runoff transformation in hydrological applications. It is found that by solely assimilating radar data, the improvement of rainfall forecasts are not as obvious as assimilating meteorological data; whereas the positive effect of radar data can be seen when combined with the traditional meteorological data, which leads to the best rainfall forecasts among the five modes. To further improve the effect of radar data assimilation, limitations of the radar correction ratio developed in this study are discussed and suggestions are made on more efficient utilisation of radar data in NWP data assimilation.

\section{Introduction}

Accurate rainfall forecasts are required in constructing a reliable flood forecasting system. This is particularly true in the flash flooding area where the forecast accuracy is highly dependent on the rapid availability of the rainfall distribution in advance (Ferraris et al., 2002). Traditionally, nowcasting methods are used in operational applications for short lead-time rainfall forecasts. Most of these methods are based on an extrapolation of the radar echoes (e.g. Dixon and 
Wiener, 1993; Mecklenburg et al., 2000). In a recent study by Germann et al. (2006b), the predictability of rainfall is examined from storm to synoptic scales through an experimental approach using continent-scale radar composite images. The lifetime of radar reflectivity patterns in Eulerian and Lagrangian coordinates are used as the measures of predictability. Later, an ensemble method is proposed by Germann et al. (2009) to characterise the residual errors in radar rainfall estimation from the perspective of flash flood forecasting. However, the common feature of radar nowcasting is statistical or empirical approaches prevail over physical approaches. This determines the nowcasting methods do not allow for the development of new storms and lose their accuracy rapidly with the increase of the forecast lead time. A comprehensive summary of various nowcasting methods can be found in the work of Ebert et al. (2004) and Mecklenburg et al. (2002).

In recent years, the mesoscale numerical weather prediction (NWP) models are gaining more and more popularity in the hydrometeorological community in providing highresolution rainfall forecasts at the catchment scale. They are capable of developing detailed precipitation fields and thus can produce forecasts with a more lasting reliability. However, the reliability of the mesoscale NWP models is largely dependent on the initial and lateral boundary conditions provided by global models as the model driving. Besides the quality of the initial and lateral boundary conditions, the accuracy of the mesoscale model is also negatively affected by the "spin-up" effect (Daley, 1991). It has been found that during the first 3 to $6 \mathrm{~h}$, the rainfall forecasts from the mesoscale NWP model are less accurate than predictions based on a simple advection of the radar echoes (Austin et al., 1987). Assimilation of suitable real-time observations into the NWP models can help significantly reduce the spin-up effect and improve the initial and lateral boundary conditions of the mesoscale model (Sokol and Pešice, 2009). Appropriate data assimilation cannot only involve the real-time observations used by the nowcasting systems (e.g. radar echoes and satellite data) into the mesoscale NWP model, but also helps initialise convective-scale events (Sokol, 2010). Weather radar plays a prominent role in revealing structures of the convective storms and the related mesoscale and microscale systems (Wakimoto et al., 2004). Xiao and Sun (2007) illustrated in their study that with the high-resolution $(2 \mathrm{~km})$ radar data assimilated into the NWP model, the convective systems could be better represented in the model initial conditions. Recent investigations in the meteorological area have shown that with the assimilation of real-time observations, especially the radar data (reflectivity or derived Doppler velocity), rainfall forecasts from the NWP models can be obviously improved for the next few hours.

Some studies focused on assimilating rainfall observations converted from the radar reflectivity data into the NWP model. Macpherson (2001) introduced the assimilation of radar-derived rainfall data into the UK Met Office's operational mesoscale model. It was found that the impact of assimilation can be detected at a forecast range of $12 \mathrm{~h}$ and increasing the frequency of rainfall data from 3-hourly to hourly largely improved the first $6 \mathrm{~h}$ forecasts. Stephan et al. (2008) assimilated the surface rainfall rates derived from the radar reflectivity data into the COSMO (Consortium for Small Scale Modelling) model. The precipitation patterns were found to be better simulated in good agreement with the radar observations for the first few hours of forecasts. Significant improvements were also made in shortrange rainfall forecasts when the radar-derived surface rainfall rates were assimilated into the $4 \mathrm{~km}$ grid length version of the Met Office Unified Model (Dixon et al., 2009). In some cases, more obvious improvements were seen when the radar reflectivity was assimilated together with Doppler radial velocity. Tong and Xue (2005) assimilated the Doppler radar observations to facilitate the forecast of a supercell storm. The best results were obtained when both radial velocity and reflectivity data were assimilated, the impact of which remained for more than $2 \mathrm{~h}$. Xiao et al. $(2005,2007)$ explored the use of the three-dimensional variational method (3D-Var) to assimilate radial velocity and radar reflectivity into MM5 (the Fifth Generation Penn State/NCAR Mesoscale Model), both of which showed positive impacts on short-range prediction of heavy rainfall events. However, without radial velocity, the assimilation of only radar reflectivity can also result in promising results. Sokol carried out a series of experiments for radar reflectivity assimilation into the COSMO model, i.e. assimilating solely radar reflectivity (Sokol and Rezacova, 2006), assimilating reflectivity together with satellite data (Sokol, 2009) and assimilating both observed and 1h-ahead extrapolated radar reflectivity (Sokol, 2010). Improvements were seen in all cases in forecasting the basic features of the storm development for at least two to three hours ahead.

However, in most of the previous studies, the improvements of the NWP rainfall forecasts after data assimilation were mainly evaluated from the meteorological aspect using synoptic analyses. For hydrological applications using the NWP rainfall forecasts in real-time flood forecasting, hydrologists are particularly concerned with the accuracy of the rainfall quantity at the catchment scale and its variations in time, both of which have direct impacts on the forecast discharge and timing of the peak flow through the rainfall-runoff transformation done by the hydrological models. Therefore, it is interesting to see how much the assimilation of the radar observations can help improve the rainfall quantity and its temporal variation in a storm event, which directly benefit the real-time flood forecasting. In this study, the potential of assimilating radar reflectivity data in improving the NWP rainfall forecasts is investigated from the hydrological aspect at the catchment scale. The radar data assimilation is compared with the assimilation of traditional meteorological observations, e.g. the surface and upper-air measurements of pressure, temperature, humidity 
and wind speed. The improvement of rainfall forecasts is also evaluated when the radar data are assimilated together with the traditional meteorological observations. Since weather radar is normally subject to errors such as bright band, attenuation of signal during high-resolution rainfall, occultation, orographic enhancement and anomalous propagation (Hitschfeld and Bordan, 1954; Browning et al., 1975; Collier, 1976; Bader and Roach, 1977; Joss and Waldvogel, 1990; Han et al., 2000), the quality of the radar data is not satisfactory compared to the rain gauge observations. Germann et al. (2006a) present the Swiss solution for the correction of real-time radar rainfall estimation in mountainous regions. Berenguer and Zawadzki $(2008,2009)$ quantified the contribution of various physical sources of uncertainty affecting radar rainfall estimates at the ground, e.g. the rangedependent error and the uncertainty due to the Z-R transformation, at a resolution typically used for radar data assimilation in mesoscale NWP models. In this study, the correction of the radar data is carried out in real-time based on the rain gauge observations before they are assimilated into the NWP model, and comparisons are made for assimilating the original and corrected radar data.

The Weather Research and Forecasting (WRF) model is the latest-generation mesoscale NWP model, which is developed under joint efforts of the scientific community based on the experiences of its predecessors, such as the widely used MM5. Nowadays WRF has gained wide recognition in mesoscale weather research and forecasting. Recent studies have shown that the WRF model has good potential in handling some rainfall features, e.g. the rainfall timing, location and evolution; however in producing the accurate rainfall quantities, the results are still not ideal (Chang et al., 2009; Hong and Lee, 2009; Shem and Shepherd, 2009; Chen et al., 2010; Liu et al., 2012a). As for data assimilation, the three/four-dimensional variational methods (3DVar/4D-Var), ensemble Kalman filter (EnKF) and latent heating nudging (LHN) are among the most effective assimilation techniques that are commonly applied to radar data (Sun, 2005). In continuous cycling mode, 3D-Var performs better in producing rational analyses of hydrometeor fields with greater computational efficiency than 4D-Var, EnKF and LHN (Barker et al., 2004; Xiao and Sun, 2007). The Mesoscale \& Microscale Meteorology division (MMM) of the US National Center of Atmospheric Research (NCAR) has developed and supports a unified model-space variational data-assimilation system for use with the WRF model, which contains the 3D-Var utility. In this study, the WRF model is used to produce the catchment-scale rainfall forecasts, driven by the operational data from the European Centre for Medium-Range Weather Forecast (ECMWF). The radar reflectivity data together with traditional meteorological observations are directly assimilated by the 3D-Var dataassimilation system in order to improve the WRF rainfall forecasts.
A $24 \mathrm{~h}$ storm event is selected from the Brue in southwest England with a drainage area of $135.2 \mathrm{~km}^{2}$. The WRF rainfall forecasts for this $24 \mathrm{~h}$ storm event before and after data assimilation are evaluated according to the rainfall quantity and its variation in time. Radar reflectivity is taken from a C-band weather radar which gives a complete coverage of the Brue catchment. The traditional meteorological observations are taken from the NCAR archives which provide global operational surface and upper-air observations. Four modes of data assimilation are carried out with the assistance of 3D-Var based on different types or combinations of observations: (1) traditional meteorological data; (2) radar reflectivity; (3) corrected radar reflectivity based on rain gauge observations; (4) a combination of the original radar reflectivity and traditional meteorological data; and (5) a combination of the corrected radar reflectivity and traditional meteorological data. The rest of the paper is organised as follows: Sect. 2 introduces the configurations of the WRF model and the functions of the 3D-Var data-assimilation system. Sect. 3 provides background information of the study catchment and the storm event, the use of the ECMWF global forecast data as the driving of the WRF model, and the NCAR and radar observations to be assimilated. The quality of the radar data is evaluated for the storm event based on the rain gauge observations, and a real-time correction ratio is developed to improve the radar data quality. The results of five modes of data assimilation are evaluated in Sect. 4, by examining the rainfall cumulative curves and the total rainfall quantities of the storm event. Discussions are made in Section 5 regarding the limitations of the radar correction ratio and enhancing the efficiency of radar data utilisation in order to further improve the NWP rainfall forecasts through data assimilation. Finally, conclusions of the paper are made in Sect. 5.

\section{The WRF model and 3D-Var data assimilation}

\subsection{WRF model set-up}

The numerical experiments of data assimilation are conducted with the Advanced Research WRF model (ARW) Version 3.1. WRF is a non-hydrostatic, primitive-equation mesoscale meteorological model with advanced dynamics, physics and numerical schemes. Detailed descriptions of the model can be found in the model manual (Skamarock et al., 2008) and also on the WRF user website (http://www. $\mathrm{mmm}$.ucar.edu/wrf/users). Sigma coordinates are adopted in the model to describe the vertical pressure levels, and a twoway nesting is allowed for the interaction between mother and child domains. In this study, three nested domains are used. Each domain is comprised of 28 vertical pressure levels with the top level set at $50 \mathrm{hPa}$. In order to decrease the modelling time and to make the results applicable in operational hydrological forecasting system, the grid size of the WRF model needs to be relatively coarse. Considering that 
lumped hydrological models are normally used in the forecasting system, in this study the grid spacing of the WRF innermost domain is set to be $10 \mathrm{~km}$. In that case the Brue catchment can be mostly covered by a single grid cell. Rainfall forecasts extrapolated from the grid cell are therefore treated as the catchment average rainfall and used for analyses.

The WRF model has options for different physical parameterisations, including microphysics, cumulus physics, surface physics, planetary boundary layer physics and radiation physics. The model performance is highly dependent on the parameterisation schemes which might be suitable for one storm event but inappropriate for others. Since it is difficult to tell the best choice for future events, the parameterisation schemes are normally fixed beforehand for operational applications. In this study, the most extensively used parameterisation schemes are used. The main physics packages include the WRF Single-Moment 3-class (WSM3) microphysics scheme (Hong et al., 2004), the new Kain-Fritsch cumulus parameterisation scheme (Kain, 2004), the Yonsei University planetary scheme for the planetary boundary layer (Hong et al., 2006), the Dudhia shortwave radiation scheme (Dudhia, 1989), and the Rapid Radiative Transfer Model (RRTM) longwave radiation scheme (Mlawer et al., 1997). Other physics options include the Monin-Obukhov scheme (Monin and Obukhov, 1954) for the description of the surface layer and the Pleim-Xiu Land Surface Model (Xiu and Pleim, 2001) to present the land surface physics.

The initial and lateral boundary conditions of the WRF model are provided by the ECMWF global operational data. ECMWF produces global 10-day forecasts based on the 00:00 and 12:00 UTC analyses (the 00:00 UTC run is only available in specific years as an experimental suite for severe weather predictions). To keep consistency with the outermost domain which has a grid spacing of $250 \mathrm{~km}$, the spatial resolution of the ECMWF products used in this study was chosen to be $2.5^{\circ} \times 2.5^{\circ}$ with a temporal resolution of $6 \mathrm{~h}$. Detailed information for the operational use of the ECMWF forecast data is given in Sect. 3.1.

\subsection{D-Var data assimilation}

Data assimilation is the technique by which observations are combined with a NWP product (called the first guess or background forecast) and their respective error statistics to provide an improved estimate (i.e. the analysis) of the atmospheric state. The variational data-assimilation technique achieves this through the iterative minimisation of a prescribed cost function (Ide et al., 1997):

$$
\begin{aligned}
J(x) & =\frac{1}{2}\left(x-x^{b}\right)^{T} \mathbf{B}^{-1}\left(x-x^{b}\right) \\
& +\frac{1}{2}\left(y-y^{0}\right)^{T} \mathbf{R}^{-1}\left(y-y^{0}\right),
\end{aligned}
$$

where $x$ is the analysis to be found that minimises the cost function $J(x), x^{b}$ is the first guess of the NWP model, $y^{0}$ is the assimilated observation and $y=H(x)$ is the modelderived observation transformed from the analysis $x$ by the observation operator $H$ for comparison against $y^{0}$. The solution of the cost function shown by Eq. (1) represents a posteriori maximum likelihood (minimum variance) estimate of the true atmosphere state given the two sources of a priori data: the first guess $x^{b}$ and the observation $y^{0}$ (Lorenc, 1986). The fit to individual observation points is weighted by the estimates of their errors, i.e. $\mathbf{B}$ and $\mathbf{R}$, which are the background error covariance matrix and the observation error covariance matrix, respectively.

The three-dimensional variational (3D-Var) system developed by Barker et al. (2004) is used in this study in tandem with the WRF model for assimilating the weather radar reflectivity and the traditional observations. Its configuration is based on an incremental formulation of the variational problem, producing a multivariate incremental analysis for pressure, wind, temperature, and relative humidity in the model space. The incremental cost function minimisation is performed in a preconditioned control variable space. The preconditioned control variables include stream function, unbalanced potential velocity, unbalanced temperature, unbalanced surface pressure and pseudo relative humidity. In the case of assimilating radar reflectivity, the total water mixing ratio $q_{t}$ is used as the moisture control variable instead of pseudo relative humidity. Equation (2) shows the observation operator adopted in the 3D-Var system for the assimilation of reflectivity (Sun and Crook, 1997):

$Z=43.1+17.5 \log \left(\rho q_{r}\right)$,

where $Z$ is the reflectivity in dBZ, $\rho$ is the air density in $\mathrm{kg} \mathrm{m}^{-3}$ and $q_{r}$ is the rainwater mixing ratio.

Equation (2) is derived analytically by assuming the Marshall-Palmer distribution of raindrop size. In practice, various empirical $Z-q_{r}$ relations have been used. However, in the current 3D-Var system, the modification of this equation is beyond the control of users. It is natural to ask how sensitive the assimilation is to the variations in the $Z-q_{r}$ relation. Since any $Z-q_{r}$ relation contains approximations, Sun and Crook (1997) varied the constants in Eq. (2) to test the sensitivity of the assimilation system to these variations. It was shown that the system was rather robust to the error caused by changes in the $Z-q_{r}$ relation, and also to the calibration errors in reflectivity. More information about the deviation and sensitivity of Eq. (2) can be found in the work of Sun and Crook $(1997,1998)$. A very recent study conducted by Wang et al. (2013) also showed that this indirect radar reflectivity assimilation scheme in 3D-Var (i.e. assimilating retrieved rainwater rather than assimilating reflectivity directly) resulted in a better performance of the retrieval procedure, and this indirect scheme helped avoid the linearisation errors of the $Z-q_{r}$ equation.

Since the total water mixing ratio $q_{t}$ is used as the control variable in the 3D-Var system, the partitioning of the moisture and hydrometeor increments is necessary during 
the minimisation procedure. A warm-rain parameterisation (Dudhia, 1989) is used in the 3D-Var system, which builds a constraint of the relations among rainwater, cloud water, moisture and temperature. When the rainwater information (from the reflectivity through Eq. 2) enters the minimisation iteration procedure, the forward warm-rain process and its backward adjoint distribute the information to the increments of other variables under the constraint of the warm-rain parameterisation scheme.

The performance of the data-assimilation system largely depends on the plausibility of the background error covariance (BE), i.e. the matrix $\mathbf{B}$ in Eq. (1). In this study, the default NCEP (National Centers for Environmental Prediction) global BE is adopted, which is named as CV3. It is estimated in the grid space using the National Meteorological Centre (NMC) method (Parrish and Derber, 1992) and is applicable for any regional domains. The control variables for $\mathrm{CV} 3$ are estimated based on the differences of $24 \mathrm{~h}$ and $48 \mathrm{~h}$ forecasts of GFS (Global Forecast System) with T170 resolution valid at the same time for 357 cases distributed over a period of one year.

\section{Study area and data}

\subsection{Study area, storm event and global forecast data}

The Brue catchment in southwest England (Fig. 1) is chosen as the study area. It is a predominantly rural catchment with a drainage area of $135.2 \mathrm{~km}^{2}$ and an elevation range between $35 \mathrm{~m}$ and $190 \mathrm{~m}$ above sea level. The average annual rainfall over the catchment is $867 \mathrm{~mm}$ from 1961 to 1990 . The catchment size and relief together with its previous history of notable storms and floods (Clark, 1996) make it a representative among the catchments in the UK requiring flood warning. In addition, a hydrological radar experiment (named HYREX) funded by Natural Environment Research Council (NERC) was run from May 1993 to April 1997 in the catchment. Data collection was extended to 2000. A dense rain gauge network (Moore et al., 2000) containing 49 Casella $0.2 \mathrm{~mm}$ tipping bucket rain gauges was set up and a C-band weather radar was located $30 \mathrm{~km}$ to the south (see Fig. 1, at Wardon Hill) which gave a complete coverage of the catchment during the project. In this study, the radar reflectivity measured by the Wardon Hill radar together with traditional meteorological observations is assimilated into the WRF model to improve the rainfall forecasts. Rainfall observations from the rain gauge network are used as the ground truth to evaluate the WRF output before and after the data assimilation.

A $24 \mathrm{~h}$ storm event which occurred over the Brue catchment on 24 October 1999 was chosen as a test case for this study. The event produced a $24 \mathrm{~h}$ rainfall accumulation of $29.38 \mathrm{~mm}$ and resulted in a peak flow of $51.31 \mathrm{~m}^{3} \mathrm{~s}^{-1}$ at the catchment outlet. The peak flow exceeded the "flood watch" threshold discharge, which is $36.03 \mathrm{~m}^{3} \mathrm{~s}^{-1}$, issued by the

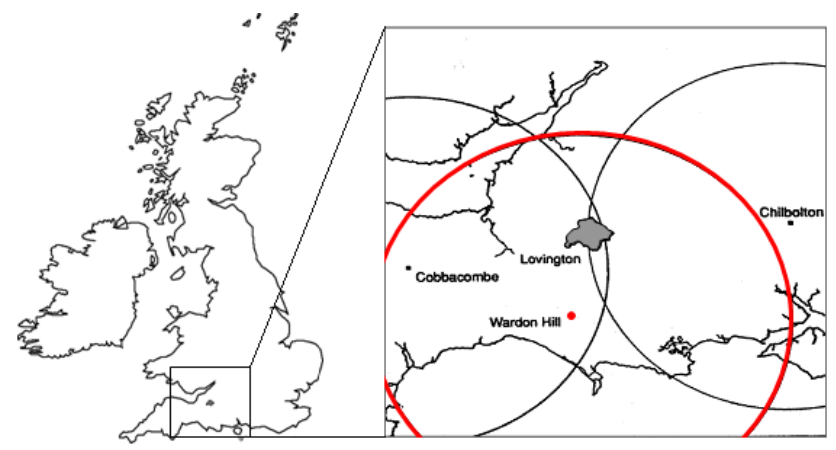

Fig. 1. Location of the Brue catchment and the Wardon Hill weather radar.

UK Environment Agency for the Brue catchment. According to the weather log of the Royal Meteorological Society (Eden, 1999), the storm happened under the control of the cyclonic weather system and was identified as a heavy thundery shower. For continuous assimilation of the real-time observations, WRF needs to run in the cycling mode in tandem with the 3D-Var system. As previously mentioned, the ECMWF operational forecast data are used as the input for the WRF model. The cycling runs of the WRF model are illustrated in Fig. 2 with the ECMWF input for continuous data assimilation in the case of the $24 \mathrm{~h}$ storm event.

In Fig. 2, there are two ECMWF forecast origins producing forecasts covering the $24 \mathrm{~h}$ duration of the storm event. It is assumed that the most recent origin can provide more accurate and reliable forecasts than the past origins. That is to say, as soon as a new origin becomes available (e.g. as time comes to 12:00 of 24 October 1999 in Fig. 2), forecasts made from the past origin (origin1) are no longer used and results of the new origin (origin2) are input into the model instead. Before the use of the forecast data from an ECMWF forecast origin, a $6 \mathrm{~h}$ spin-up period (as shown by the dashed lines as parts of run1 and run6 in Fig. 2) is adopted to provide a better state of the model control variables. Data used for the $6 \mathrm{~h}$ spin-up are the $40 \mathrm{yr}$ re-analysis data from ECMWF (ERA-40). In Fig. 2, run1 and run6 are the original runs of the WRF model using the ECMWF forecast data respectively from origin1 and origin2. Data assimilation starts at 12:00 of 23 October 1999 and happens onwards with a time interval of $6 \mathrm{~h}$. The data-assimilation times are marked with circles in Fig. 2. The remaining six runs (run2, run3, run4, run5, run7 and run8) are data-assimilation runs, generating the updated results after assimilating observations at the starting time of each run. For the cycling mode of WRF, the boundary files of the data-assimilation runs are generated from their previous runs. In this way the information of the assimilated observations in previous runs can be kept and delivered to the follow-on runs. 
Table 1. Number of NCAR data records distributed inside each of the triple nested domains.

\begin{tabular}{|c|c|c|c|c|c|c|c|}
\hline \multirow{2}{*}{\multicolumn{2}{|c|}{$\begin{array}{c}\text { Data assimilation } \\
\text { time }\end{array}$}} & \multicolumn{3}{|c|}{ Surface data records } & \multicolumn{3}{|c|}{ Upper-air data records } \\
\hline & & \multirow{2}{*}{$\begin{array}{r}\text { Dom1 } \\
75\end{array}$} & \multirow{2}{*}{$\frac{\text { Dom2 }}{8}$} & \multirow{2}{*}{$\begin{array}{r}\text { Dom3 } \\
0\end{array}$} & \multirow{2}{*}{$\begin{array}{r}\text { Dom1 } \\
1873\end{array}$} & \multirow{2}{*}{$\begin{array}{r}\text { Dom2 } \\
233\end{array}$} & \multirow{2}{*}{$\begin{array}{r}\text { Dom3 } \\
2\end{array}$} \\
\hline Time 1 & $23 / 1012: 00$ & & & & & & \\
\hline Time 2 & $23 / 1018: 00$ & 51 & 7 & 0 & 1744 & 213 & 2 \\
\hline Time 3 & 23/10 00:00 & 78 & 8 & 0 & 1416 & 186 & 2 \\
\hline Time 4 & 24/10 06:00 & 58 & 7 & 0 & 1819 & 218 & 2 \\
\hline Time 5 & 24/10 12:00 & 78 & 8 & 0 & 1871 & 233 & 2 \\
\hline Time 6 & 24/10 18:00 & 50 & 6 & 0 & 1780 & 215 & 1 \\
\hline
\end{tabular}

\subsection{NCAR surface and upper-air observations}

The US National Center of Atmospheric Research (NCAR) archives operational global meteorological observations which are freely downloadable and suitable for use in realtime cases. The surface and upper-air data assimilated in this study are obtained respectively from the "ds353.4" and "ds464.0" datasets, which contain the surface and upper-air measurements of pressure, temperature, humidity and wind from fixed and mobile land/sea stations. The data are initially downloaded in ADP format and then converted into LITTLE_R format before they are assimilated in the 3D-Var system. Table 1 shows the number of NCAR data records located in each of the triple nested domains at the six dataassimilation times marked in Fig. 2.

It can be seen from Table 1 that the number of data records decreases obviously from the outermost to the innermost domain. The majority of records is distributed in the two outer domains, with quite few data found in the innermost domain. For the surface observations, there is even no data record in the innermost domain. It should be mentioned that in this study the WRF model is run with two-way nesting, which allows for interaction and information exchange between the coarse and fine domain. Therefore, data assimilated by the two outer domains can finally benefit the innermost domain. The quality control of the assimilated observations is realised by defining the observation error covariance, i.e. the matrix $R$ of Eq. (1) in the 3D-Var system. The US Air Force (AFWA) OBS error file is used in this study for the NCAR surface and upper-air observations, which defines the instrumental and sensor errors for various air, water and surface observation types as well as satellite retrievals.

\subsection{Weather radar data and the radar correction ratio}

The radar reflectivity to be assimilated is from the Wardon Hill radar. The radar cycles through 4 different scan elevations $\left(0.5^{\circ}, 1.0^{\circ}, 1.5^{\circ}, 2.5^{\circ}\right)$ every $5 \mathrm{~min}$ up to a range of $210 \mathrm{~km}$. The $3 \mathrm{~dB}$ radar beam width is $1.0^{\circ}$. For the lowest scan elevation of $0.5^{\circ}$, the radar beam height above the Brue catchment is approximately $0.4 \mathrm{~km}$. The local software at the radar site converts the measurements of reflectivity from radial grids to two Cartesian grids: a $76 \times 76$ grid of $2 \mathrm{~km}$ square pixels covering a radius of $76 \mathrm{~km}$ and an $84 \times 84$ grid of $5 \mathrm{~km}$

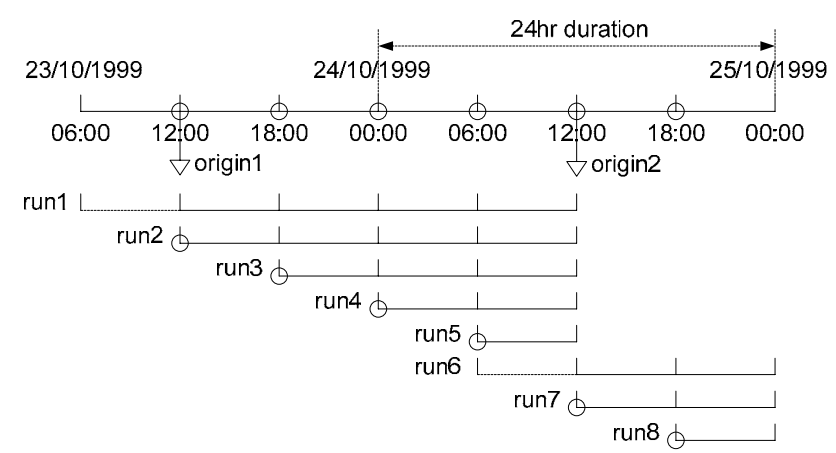

Fig. 2. Time bars of the cycling WRF runs for continuous data assimilation using the ECMWF operational forecast data.

square pixels covering a radius of $210 \mathrm{~km}$. Figure 3 shows the radar images from the lowest scan $\left(0.5^{\circ}\right)$ on the $2 \mathrm{~km}$ Cartesian grid at the six data-assimilation times of the storm event. The colour of each pixel (with an area of $2 \times 2 \mathrm{~km}^{2}$ ) represents the rainfall intensity in the unit of $\mathrm{mm} / 5 \mathrm{~min}$. The red circle in the centre of the image shows the location of the Wardon Hill radar $\left(50.49^{\circ} \mathrm{N}, 2.33^{\circ} \mathrm{W}\right.$, with an altitude of $255 \mathrm{~m}$ above the sea level). The Brue catchment (outlined in red) is located in a radar sector free of beam blocking and ground clutter for all the four scans (Borga et al., 2002). In this study, the radar reflectivity shown by the six images in Fig. 3 is assimilated into WRF with a time interval of $6 \mathrm{~h}$.

The number of the $2 \mathrm{~km}$ pixels located in the three nested domains are 4418,4418 and 441 from the outermost to the innermost. The identical number for the two outer domains is due to the complete coverage of the radar image by those two domains. When the reflectivity is assimilated in the 3DVar system, the latitude and longitude at the central point of each pixel and the height of the radar beam above that pixel need to be stated together with the corresponding reflectivity. It should be mentioned that a thorough quality control of the radar data has been carried out throughout the HYREX experiment to remove invalid and missing data due to anomalous propagation and technical problems leading to disruption of the radar image and the lack of radar response.

As aforementioned, there were 49 rain gauges in the Brue catchment during the HYREX project. The catchment areal rainfall obtained from the rain gauge network by the Thiessen polygon method can be used for a preliminary examination of the radar data quality. It should be mentioned that during the HYREX experiment, software at the Wardon Hill radar site converted the measured reflectivity directly into rainfall rates based on the following $Z-R$ relationship:

$Z=200 \times R^{1.6}$,

where $Z$ and $R$ are the reflectivity in $\mathrm{mm}^{6} \mathrm{~m}^{-3}$ and the rainfall rate in $\mathrm{mm} \mathrm{h}^{-1}$. Equation (3) is the original form of the Marshall-Palmer equation. A detailed description of the signal processing during the HYREX experiment (including 


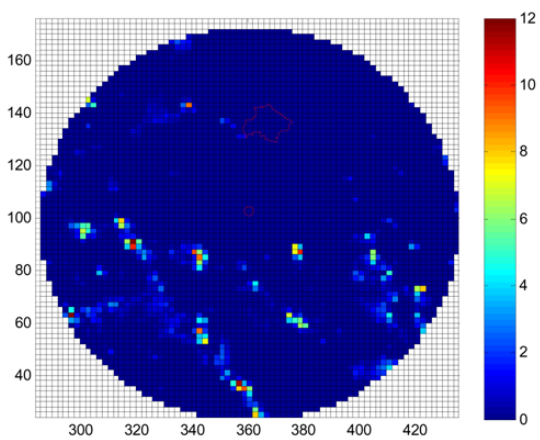

(a) Time 1: 23/10/1999 12:00

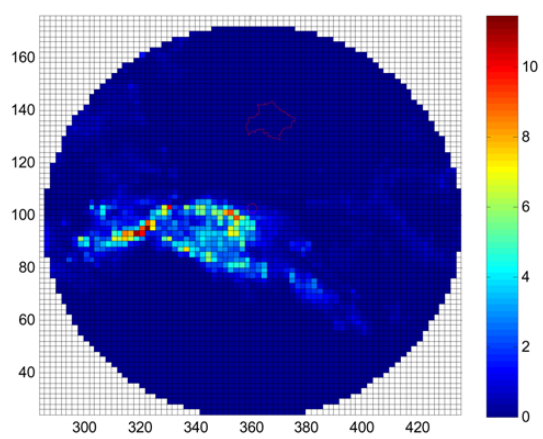

(c) Time 3: 24/10/1999 00:00

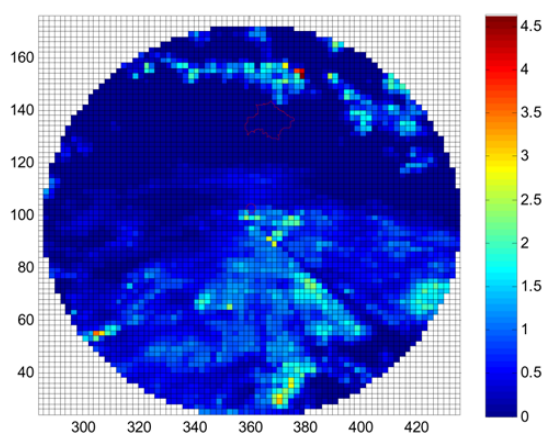

(e) Time 5: 24/10/1999 12:00

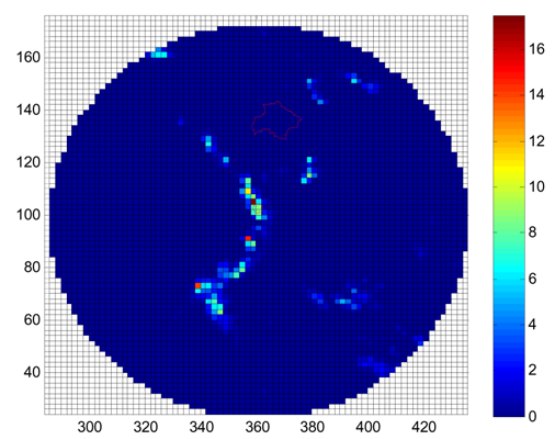

(b) Time 2: 23/10/1999 18:00

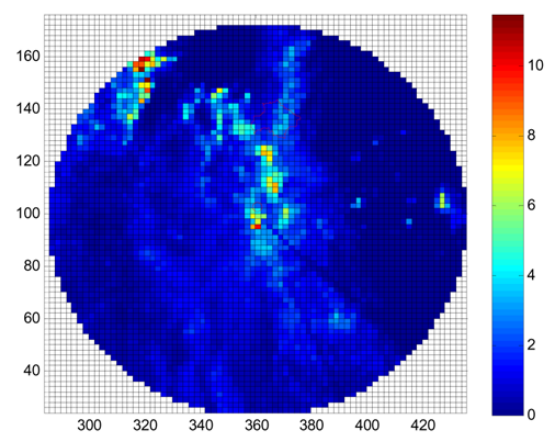

(d) Time 4: 24/10/1999 06:00

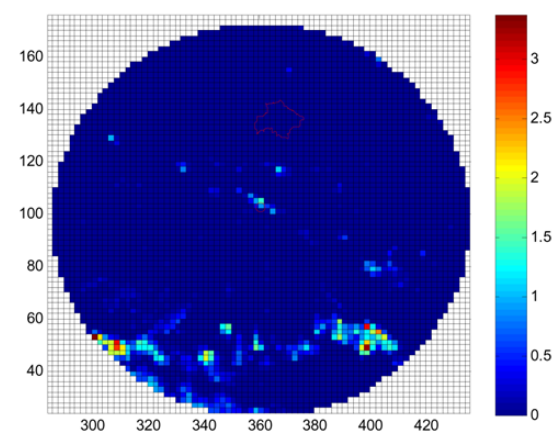

(f) Time 6: 24/10/1999 18:00

Fig. 3. Radar images of the lowest scan $\left(0.5^{\circ}\right)$ on the $2 \mathrm{~km}$ Cartesian grid at the six data-assimilation times of the storm event (mm/5 min).

the Marshall-Palmer $Z-R$ conversion) is given by Brown et al. (1991) and Kitchen and Jackson (1993). The MarshallPalmer equation is found to be appropriate to be used in southwest England, which has been proven by a series of follow-on studies based on the converted HYREX radar dataset (Wood et al., 2000; Wheater et al., 2000; Bell and Moore, 2000a, b; Borga, 2002; Borga et al., 2002). Moreover, the observation operator for reflectivity assimilation in 3D-Var, i.e. Eq. (2), is derived based on the Marshall-Palmer raindrop size distribution. To keep consistency with that, the converted rainfall rates from the Wardon Hill radar following Eq. (3) are used to make a comparison with the gauge observations.

Figure 4 shows the comparison between the gauge- and radar-estimated rainfall for the $24 \mathrm{~h}$ storm event. The time series bars are shown in Fig. 4a and the spatial distributions of the $24 \mathrm{~h}$ rainfall accumulations are shown in Fig. $4 \mathrm{~b}$ and $\mathrm{c}$, respectively, for the gauge and radar observations. Obvious underestimation of the Wardon Hill radar can be noticed by comparing the spatial distributions of the gauge- and radarestimated rainfall in Fig. $4 \mathrm{~b}$ and c. However, the time series bars in Fig. 4a show a good consistency of the radar with the rain gauges in estimating the rainfall occurrences and the temporal variances of the rainfall rate. For this reason, the assimilation of the radar reflectivity is still expected to have some positive effect on improving the rainfall forecasts from the WRF model.

As pointed out by Borga et al. (2002), the underestimation of the Wardon Hill radar in the Brue catchment is mainly caused by the non-uniform vertical profile of reflectivity, the orographic enhancement of precipitation, the radar calibration stability effects and the uncertainty in $Z-R$ conversion. 

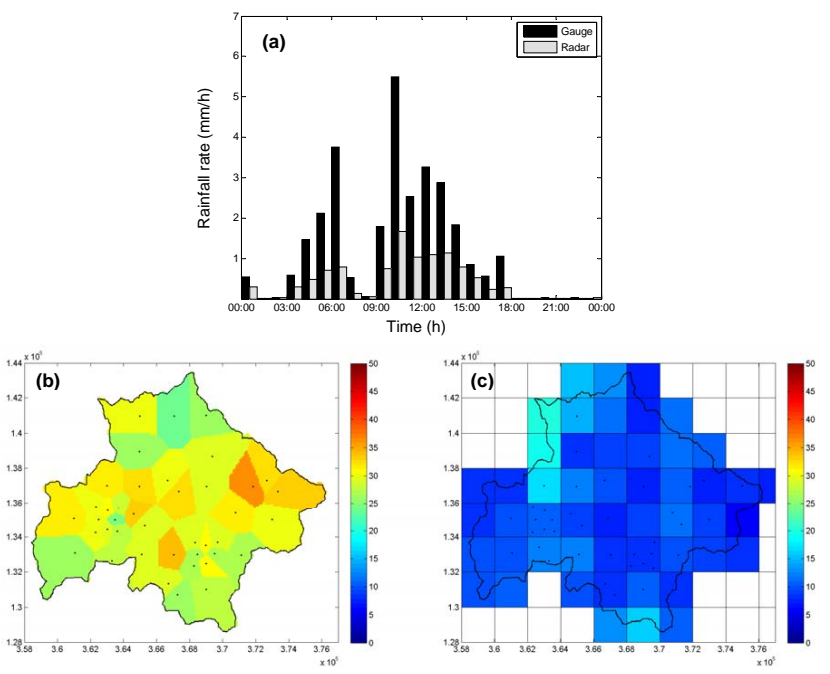

Fig. 4. Comparison of the Wardon Hill radar and the rain gauge network: (a) time series bars of the hourly catchment areal rainfall; (b) $24 \mathrm{~h}$ rainfall accumulation observed by the rain gauge network (mm); (c) $24 \mathrm{~h}$ rainfall accumulation measured by the weather radar $(\mathrm{mm})$.

To better improve the radar data quality, a real-time correction ratio is developed to correct the radar bias at each dataassimilation time based on the rain gauge observations:

correction_ratio $=\frac{R 6 \mathrm{~h}_{\text {gauge }}}{R 6 \mathrm{~h}_{\text {radar }}}$,

where $R 6 \mathrm{~h}_{\text {gauge }}$ and $R 6 \mathrm{~h}_{\text {radar }}$ represent the accumulative amounts of the catchment average rainfall during the antecedent $6 \mathrm{~h}$ of the assimilation time, based on the observations from rain gauges and radar, respectively. The duration of $6 \mathrm{~h}$ is chosen as a compromise between the real-time representativeness and stability of the correction ratio. This correction ratio is directly multiplied to the $2 \mathrm{~km}$ pixel-based rainfall rates measured by the Wardon Hill radar on the whole scan range before they are converted into the reflectivity. The values of the radar correction ratio at the six data-assimilation times for the $24 \mathrm{~h}$ storm event are shown in Table 2. For a more stable correction, the ratio is limited to a range from 0.3 to 3. In Table 2, the correction ratio varies from 1.96 to 3.21, which also reveals obvious underestimation of the Wardon Hill radar: the radar-estimated rainfall is less than half of the gauge-observed values at the six data-assimilation times.

In this study, both the original and the corrected radar reflectivity data are assimilated into the WRF model to see if the radar data can help improve the rainfall forecasts. Comparisons are further made on the improvement by assimilating the corrected and the original radar data. Since the realtime radar correction ratio is applied directly on the radar data, no measurement error is assumed when defining the observation error covariance in the 3D-Var system.

\section{Results}

With the NCAR observations and the original and corrected radar reflectivity data, 3D-Var data assimilation is carried out for the $24 \mathrm{~h}$ storm event in the following five modes:

1. Mode 1: assimilating NCAR surface and upper-air observations only;

2. Mode 2: assimilating the original radar reflectivity data only;

3. Mode 3: assimilating the corrected radar reflectivity data only;

4. Mode 4: assimilating both NCAR observations and the original radar data; and

5. Mode 5: assimilating both NCAR observations and the corrected radar data.

The improvements of the WRF rainfall forecasts by applying the five modes of data assimilation are examined in this section. Besides the different assimilated data, there is no other difference in the five modes regarding the settings of the WRF model and the 3D-Var system. The purpose is to find which type of observations (or a combination of two types) is more effective in improving the accuracy of the forecasted rainfall. For processing the WRF output, in the beginning, WRF outputs are extracted at the same locations of the 49 rain gauges and then averaged using the Thiessen polygon method to get the catchment areal rainfall. It is found that the averaged WRF results have very little differences compared to those extracted from the central single grid cell with more than $60 \%$ coverage of the Brue catchment in area. For simple calculation, the rainfall forecasts extrapolated from that single grid cell are therefore treated as the catchment areal rainfall and used for analyses. Since the temporal variation and total amount of the rainfall prediction are of more importance in operational use (e.g. in real-time flood forecasting), the following analyses and comparisons are based on the cumulative curves and the total cumulative amounts of the catchment areal rainfall. No investigation of the rainfall improvement in the spatial dimension after data assimilation is made.

\subsection{Cumulative curves of the catchment areal rainfall}

The presumed trends of the rainfall cumulative curves after data assimilation are shown in Fig. 5 for the WRF cycling runs illustrated in Fig. 2. For better comparison, an extension of $12 \mathrm{~h}$ is added to each of the WRF runs in order to show clearer trends of the rainfall cumulative curves. In Fig. 5, the black line indicates the cumulative curve of the catchment areal rainfall obtained by averaging the rain gauge observations using the Thiessen polygon method. It is treated as the ground truth for evaluating the WRF results. As shown by 
Table 2. Correction ratios for the Wardon Hill radar data at the dataassimilation times.

\begin{tabular}{ccrrr}
\hline Data-assimilation time & $\begin{array}{r}\text { Gauge } \\
(\mathrm{mm})\end{array}$ & $\begin{array}{r}\text { Radar } \\
(\mathrm{mm})\end{array}$ & $\begin{array}{r}\text { Correction ratio } \\
\text { (gauge/radar) }\end{array}$ \\
\hline Time 1 & $23 / 10 / 1999,12: 00$ & 5.08 & 2.14 & 2.38 \\
Time 2 & $23 / 10 / 1999,18: 00$ & 2.19 & 1.11 & 1.96 \\
Time 3 & $24 / 10 / 1999,00: 00$ & 1.21 & 0.54 & 2.23 \\
Time 4 & $24 / 10 / 1999,06: 00$ & 4.72 & 1.83 & 2.58 \\
Time 5 & $24 / 10 / 1999,12: 00$ & 14.16 & 4.41 & $3.21^{*}$ \\
Time 6 & $24 / 10 / 1999,18: 00$ & 10.42 & 4.05 & 2.57 \\
\hline
\end{tabular}

Note: * correction ratios larger than 3 are limited to 3 ; the gauge and radar observations at each data-assimilation time represent the accumulative amounts for the previous $6 \mathrm{~h}$.

Fig. 2, run1 and run6 are the WRF original runs without data assimilation, driven by ECMWF global data from two different forecast origins. These two runs are represented by solid curves in Fig. 5. The remaining colour lines are the cumulative curves of the data-assimilation runs, which are solid lines at the beginning and then become dashed after the next data assimilation. It is assumed that after each time of data assimilation which happens every $6 \mathrm{~h}$, the rainfall forecasts from the new run are closer to the ground truth than the previous runs. That is why the solid curve becomes dashed after $6 \mathrm{~h}$ when the forecasts from a new data-assimilation run are available. By assuming the WRF original run gives an underestimated accumulation of the catchment areal rainfall, the following runs show a gradual uplifting of the original curve as a result of the continuous data assimilation by the $3 \mathrm{D}-\mathrm{Var}$ system.

The purpose of Fig. 5 is only to show the symbols and the meanings of the different WRF runs. In reality, the curves may vary considerably from the presumed ones. Figure 6 presents the actual curves of the catchment areal rainfall of the original WRF runs and after the five modes of 3DVar data assimilation. Only results of the innermost domain (Dom3) are shown. Results of the two outer domains have similar trends as the innermost domain, thus their cumulative curves are not shown in this section, while the total cumulative amounts in all the three domains are later summarised and compared in Sect. 4.2. In Fig. 6, the same symbols are used as those shown in Fig. 5. The curve in light grey represents the rainfall accumulation estimated by the Wardon Hill radar. The radar reflectivity is transformed into the rainfall rate following the $Z-R$ relation shown by Eq. (3).

Using the ECMWF operational forecast data as the driving of the WRF model, the original runs (i.e. run1 and run6 in all the subfigures of Fig. 6) are much worse than expected. Almost no rainfall is produced by the original runs without assimilating any data. When the NCAR observations are assimilated as Mode 1, significant improvement can be seen in Fig. 6a. However, the results are not satisfactory since the final cumulative amount (see the curve of run8 in Fig. 6a) is still less than the radar-estimated value. The case is worse

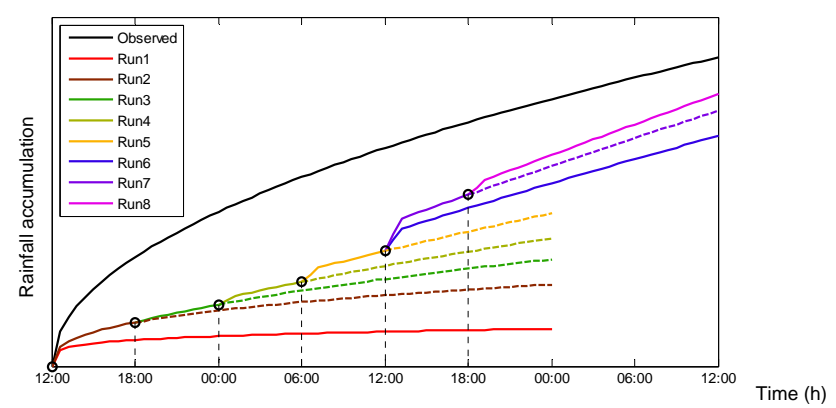

Fig. 5. Presumed trends of the rainfall cumulative curves after data assimilation.

with the radar data. For Mode 2 in Fig. 6b, the assimilation of the radar reflectivity does not show any positive effect. Even using the corrected radar data (Mode 3 in Fig. 6c), the improvement is negligible. However, the best results are achieved by assimilating both the NCAR observations and the radar reflectivity. In Fig. 6d and e, the data-assimilation runs show a gradual increase following similar trends as the ground truth, i.e. the black curve of the gauge observations. The most obvious case is run5, which generates rainfall in a very consistent pattern with the ground truth, although there is a little difference with respect to the rainfall quantities. For Mode 4 in Fig. 6d, the final cumulative amount is increased to $88 \%$ of the gauge-observed value; and for Mode 5 in Fig. 6e, the cumulative amount also exceeds the radarestimated value and is up to $55 \%$ of the gauge observation. Against expectations, when combined with the NCAR observations, the corrected radar reflectivity does not perform better in improving the rainfall forecasts than the original radar data.

To further investigate the performances of data assimilation in different modes, the amount of data assimilated in each of the five modes is examined. Table 3 summarises the number of data actually assimilated in the five modes of 3DVar at the six assimilation times of the storm event. As expected, the amount of assimilated data decreases from the outermost domain (Dom1) to the innermost domain (Dom3). The number of data assimilated is also highly related to the data validity and quality. For some data-assimilation times such as Time 1, Time 2 and Time 6, the radar data assimilated are much less than those assimilated at the other assimilation times in Mode 2 and Mode 3. The reason can be found by examining the radar images in Fig. 3. Since there is less rainfall observed by the radar (i.e. more zero pixels in the images) in Fig. 3a, b and f, the number of data assimilated at these assimilation times is much less that the other cases.

For the comparison of the number of data assimilated in different modes, it is expected that the data assimilated in Mode 4 should be equal to a sum of the data assimilated in the corresponding domain of Mode 1 and Mode 2 (ditto for Mode 5, the number of data assimilated should be a sum 
Table 3. Number of observations actually assimilated in each of the triple nested domains.

\begin{tabular}{|c|c|c|c|c|c|c|c|}
\hline & & $\begin{array}{r}\text { Time } 1 \\
23 / 1012: 00\end{array}$ & $\begin{array}{r}\text { Time } 2 \\
23 / 1018: 00\end{array}$ & $\begin{array}{r}\text { Time } 3 \\
24 / 1000: 00\end{array}$ & $\begin{array}{r}\text { Time } 4 \\
24 / 1006: 00\end{array}$ & $\begin{array}{r}\text { Time } 5 \\
24 / 1012: 00\end{array}$ & $\begin{array}{r}\text { Time } 6 \\
24 / 1018: 00\end{array}$ \\
\hline \multirow[t]{3}{*}{ Mode 1} & Dom1 & 11487 & 8933 & 12231 & 9553 & 11604 & 8717 \\
\hline & Dom2 & 1620 & 1689 & 1618 & 1605 & 1701 & 1603 \\
\hline & Dom3 & 3 & 5 & 3 & 5 & 5 & 3 \\
\hline \multirow[t]{3}{*}{ Mode 2} & Dom1 & 379 & 194 & 488 & 2288 & 1762 & 241 \\
\hline & Dom2 & 389 & 197 & 494 & 2284 & 1770 & 251 \\
\hline & Dom3 & 4 & 20 & 0 & 156 & 63 & 4 \\
\hline \multirow[t]{3}{*}{ Mode 3} & Dom1 & 385 & 242 & 875 & 1232 & 1436 & 338 \\
\hline & Dom2 & 395 & 251 & 884 & 1246 & 1437 & 348 \\
\hline & Dom3 & 1 & 22 & 1 & 74 & 65 & 9 \\
\hline \multirow[t]{3}{*}{ Mode 4} & Dom1 & 11866 & 9068 & 12625 & 11484 & 13366 & 8144 \\
\hline & Dom2 & 2009 & 1870 & 1569 & 3003 & 3471 & 1503 \\
\hline & Dom3 & 7 & 24 & 3 & 236 & 68 & 6 \\
\hline \multirow[t]{3}{*}{ Mode 5} & Dom1 & 11872 & 9174 & 13086 & 11522 & 13040 & 8972 \\
\hline & Dom2 & 2015 & 1960 & 1625 & 3159 & 3138 & 1882 \\
\hline & Dom3 & 4 & 25 & 4 & 88 & 70 & 12 \\
\hline
\end{tabular}
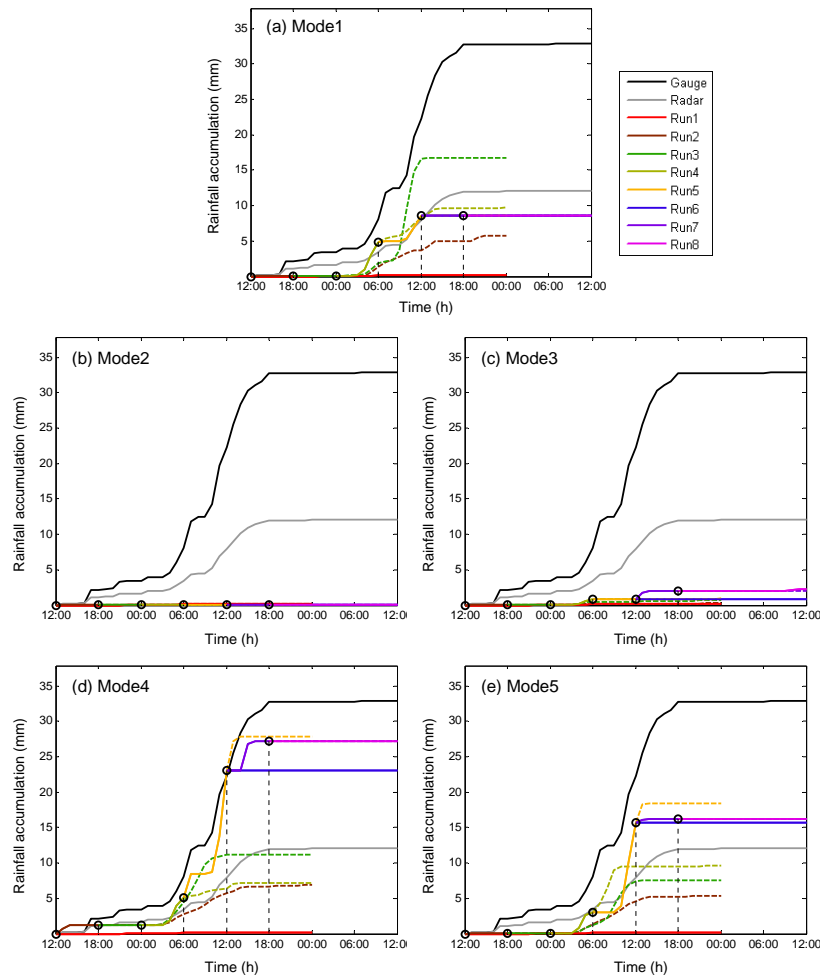

Fig. 6. Cumulative curves of the forecast rainfall after applying the five modes of data assimilation from 23 October 1999 at 12:00 to 25 October 1999 at 12:00.

of those assimilated in Mode 1 and Mode 3). However, as shown by Table 3, Mode 4 and Mode 5 do not assimilate the same numbers of data as expected. Also, the number of data assimilated in Mode 2 does not equal to that in Mode 3, and Mode 4 does not equal to Model 5. This is caused by the consistency checking of the observations with the WRF first guesses and the removal of the duplicate and conflict observations before the assimilation takes place. Similarly, it can also be found that for Mode 2 and Mode 3 (assimilating radar data only) in Table 3, the radar data assimilated by Dom 2 is slightly more than that assimilated by Dom1 for all the assimilation times, although the same number of radar data is located in the two domains (as mentioned, 4418). This is probably due to the difference of the horizontal resolution between the domain and the radar image. Compared to Dom2 (with a resolution of $50 \mathrm{~km})$, there might be more radar data $(2 \mathrm{~km}$ resolution) deemed to be redundant in Dom1 $(250 \mathrm{~km}$ resolution) by the 3D-Var system. As a consequence, less data are actually assimilated in Dom1 than Dom2.

\subsection{Error quantification using the $24 \mathrm{~h}$ rainfall totals}

For a more quantitative evaluation of the five modes of data assimilation, the total cumulative amounts of the catchment areal rainfall are calculated for the $24 \mathrm{~h}$ duration of the storm event. The results are shown in Table 4, which summarises the $24 \mathrm{~h}$ rainfall totals observed by the rain gauges and the Wardon Hill radar, and also rainfall totals produced by WRF before and after data assimilation of the five modes. The WRF results in all the three nested domains are presented in the table. It should be mentioned that when calculating the rainfall totals for the data-assimilation runs, the first six hours of the runs covering the duration of the storm event are used; i.e. the first six hours of run4, run5, run7 and run8 are used to calculate the $24 \mathrm{~h}$ accumulation after data assimilation. This guarantees that for each $6 \mathrm{~h}$ period of the storm duration, the 
Table 4. Cumulative amounts (in $\mathrm{mm}$ ) of rainfall observations and forecasts for the $24 \mathrm{~h}$ storm duration.

\begin{tabular}{lllll}
\hline & & Dom1 & Dom2 & Dom3 \\
\hline Observations & Rain gauge & 29.38 & 29.38 & 29.38 \\
& Radar & 10.36 & 10.36 & 10.36 \\
\hline \multirow{2}{*}{ WRF forecasts } & Original run & $1.27(-96 \%)$ & $0.23(-99 \%)$ & $0.15(-99 \%)$ \\
& 3D-Var Mode 1 & $6.11(-79 \%)$ & $8.34(-72 \%)$ & $8.52(-71 \%)$ \\
& 3D-Var Mode 2 & $0.16(-99 \%)$ & $0.01(-100 \%)$ & $0.00(-100 \%)$ \\
& 3D-Var Mode 3 & $3.78(-87 \%)$ & $2.26(-92 \%)$ & $1.95(-93 \%)$ \\
& 3D-Var Mode 4 & $20.21(-31 \%)$ & $24.61(-16 \%)$ & $25.95(-12 \%)$ \\
& 3D-Var Mode 5 & $16.82(-43 \%)$ & $16.13(-45 \%)$ & $16.17(-45 \%)$ \\
\hline
\end{tabular}

latest updating results are adopted. Similarly, when calculating the rainfall accumulation for the WRF original runs (i.e. run1 and run6), the downscaled results from the most recent ECMWF origins are used; e.g. the results of run1 are used the first two $6 \mathrm{~h}$ intervals of the storm duration, whereas the results of run 6 are used for the last two $6 \mathrm{~h}$ intervals.

The $24 \mathrm{~h}$ accumulation observed by the rain gauges is treated as the ground truth to calculate the relative errors of the WRF original run and the 3D-Var runs of different modes, as shown in the brackets in Table 4. The original run of WRF produces quite little rainfall, with the accumulative errors being $-96 \%,-99 \%$ and $-99 \%$ in the three nested domains. After assimilating the observations, obvious improvements can be seen in the $24 \mathrm{~h}$ totals of the catchment areal rainfall. When comparing the five modes of 3D-Var, the conclusions made in Sect. 4.1 can be further verified quantitatively by the $24 \mathrm{~h}$ accumulative amounts and their corresponding errors in Table 4 . The assimilation of the combinations of NCAR and radar data are found to generate better results than assimilating each single type of the data. Compared to Mode 5 which assimilates the corrected radar data, Mode 4 shows better capability in improving the rainfall forecasts by combining the NCAR observations with the original radar data. The accumulative errors in Mode 4 are $-31 \%,-16 \%$ and $-12 \%$ from the outermost to the innermost domain, which are the best results among the five 3D-Var modes. For the cases assimilating one type of observations only, Mode 1 (using NCAR observations) performs better than Mode 2 and Mode 3 (assimilating respectively original and corrected radar data). Although the $24 \mathrm{~h}$ rainfall totals are increased after applying the radar correction ratios in Mode 3, the improvements are not obvious. Compared to Mode 2, the accumulative errors are only reduced by $12 \%, 8 \%$ and $7 \%$ in the three nested domains in Mode 3. For the difference of the $24 \mathrm{~h}$ rainfall totals in different domains, except for Mode 1 and Mode 4 where the rainfall forecasts are improved from the outermost to the innermost domain, there is no big difference in the three nested domains in the other modes of 3D-Var.

The reason for the unsatisfactory results of assimilating the radar data (i.e. the worse results of Mode 2 and Mode 3 compared with Mode 1) might lie with the inefficient utilisation of the radar data with the current assimilation frequency (i.e. the time interval of $6 \mathrm{~h}$ for radar data assimilation). As aforementioned, the Wardon Hill radar completes an azimuthal scan at certain elevation every $5 \mathrm{~min}$. In this case, the assimilation of the radar data is technically possible at a time interval as short as $5 \mathrm{~min}$. More frequent data assimilation with a shortened time interval can help include more useful information of the rainfall formation process and thus might further improve the rainfall forecasts of the WRF model (Liu et al., 2012b). As for the correction of the radar data using the correction ratio developed in this study, it had been expected that the assimilation of the corrected data could lead to better rainfall improvement compared to the original data. When assimilating only the radar data in Mode 2 and Mode 3, the results are better using the corrected radar data in Mode 3, although the improvement is not significant. However, when combining the radar data with the NCAR observations, the use of the corrected radar data in Mode 5 does not show any advantage compared with using the original radar data in Mode 4. The limitations of the radar correction ratio are investigated in the following section, and discussions are made on more effective correction and efficient utilisation of the radar data in data assimilation of the NWP model.

\section{Discussion}

The real-time correction ratio of the radar reflectivity adopted in this study has limitations itself. The radar errors are obtained by examining the difference between the gauge- and radar-observed rainfall accumulations from the Brue catchment (with an area of $135.2 \mathrm{~km}^{2}$ ), which are then used to correct the whole radar image $(2 \mathrm{~km} \times 2 \mathrm{~km}$ pixels covering an area with a radius of $76 \mathrm{~km}$ ). This is actually not appropriate since the radar error in the Brue catchment cannot be approved to be representative of the errors in the whole radar scan range. In addition, the use of the catchment average error to correct each single pixel value also brings uncertainties. However, this is the best that can be done considering the current availability of the gauge observations. The correction ratio used in this study is only a preliminary trial for 
improving the quality of the radar data. With more observations available beyond the Brue catchment, the correction could be more promising. Moreover, since only the WRFforecasted rainfall in the Brue catchment is examined, further investigation of the WRF results over an extended area might help find more obvious improvement after the assimilation of the corrected radar data.

It is noteworthy that this gauge-based correction ratio only accounts for the mean-field bias of the radar data, which is normally generated due to the beam height above the ground, the deviation of the $Z-R$ relationship, and the imperfect radar calibration (Anagnostou et al., 1998; Seo et al., 1999). It should be mentioned that for radar data assimilation, the rainfall rates estimated by the Wardon Hill radar have to be converted back into reflectivities before they are assimilated by WRF-3D-Var. If the underestimation of the Wardon Hill radar found in this study is largely caused by the biased $Z-R$ relationship, then the application of the correction ratio could make the case even worse when the corrected rainfall rates are converted back into reflectivities following the original biased $Z-R$ relationship. This may to some extent explain why the assimilation results are not much improved when using the corrected radar data in Mode 3. Moreover, the gaugebased radar adjustment can be best applied only when the homogeneity in the accuracy of the radar rainfall estimates with respect to range and scanning elevation is ensured (Borga et al., 2002). For further improvement, the range-dependent errors associated with the non-uniform vertical profile of reflectivity and beam attenuation should be corrected before the adjustment of the mean-field bias. In addition, considering the complex terrain of the study area, the orographic enhancement may only be partially detected or entirely missed by the Wardon Hill radar. Therefore, a physically based adjustment scheme could help take into account the low-level orographic growth and further improve the radar measurements (Kitchen et al., 1994).

For a more efficient utilisation of the weather radar observations for data assimilation, as mentioned in the previous section, the assimilation time interval could be shortened. This is of great importance to short-duration storms with large rainfall intensities. Figure 7 shows a highly convective storm that happened during a $24 \mathrm{~h}$ period from 3 August 1994 at 12:00 to 5 August 1994 at 12:00 in the Brue catchment (Liu et al., 2012b). The time series bars of the catchment areal rainfall observed by both the rain gauges and the Wardon Hill radar are shown in Fig. 7a. The majority of rain fell in one hour from 22:00 to 23:00 on 3 August 1994 with very large intensity. The cumulative curves of the WRF rainfall outputs for this convective event before and after data assimilation are shown in Fig. 7b. Run1 and run4 are original runs using forecast data from two ECMWF origins; the others are data assimilation runs with both NCAR and radar reflectivity data assimilated at a $6 \mathrm{~h}$ interval. The curves in Fig. $7 \mathrm{~b}$ show very poor assimilation results: only a small amount of rainfall appears after 06:00 on 4 August 1994, which is not
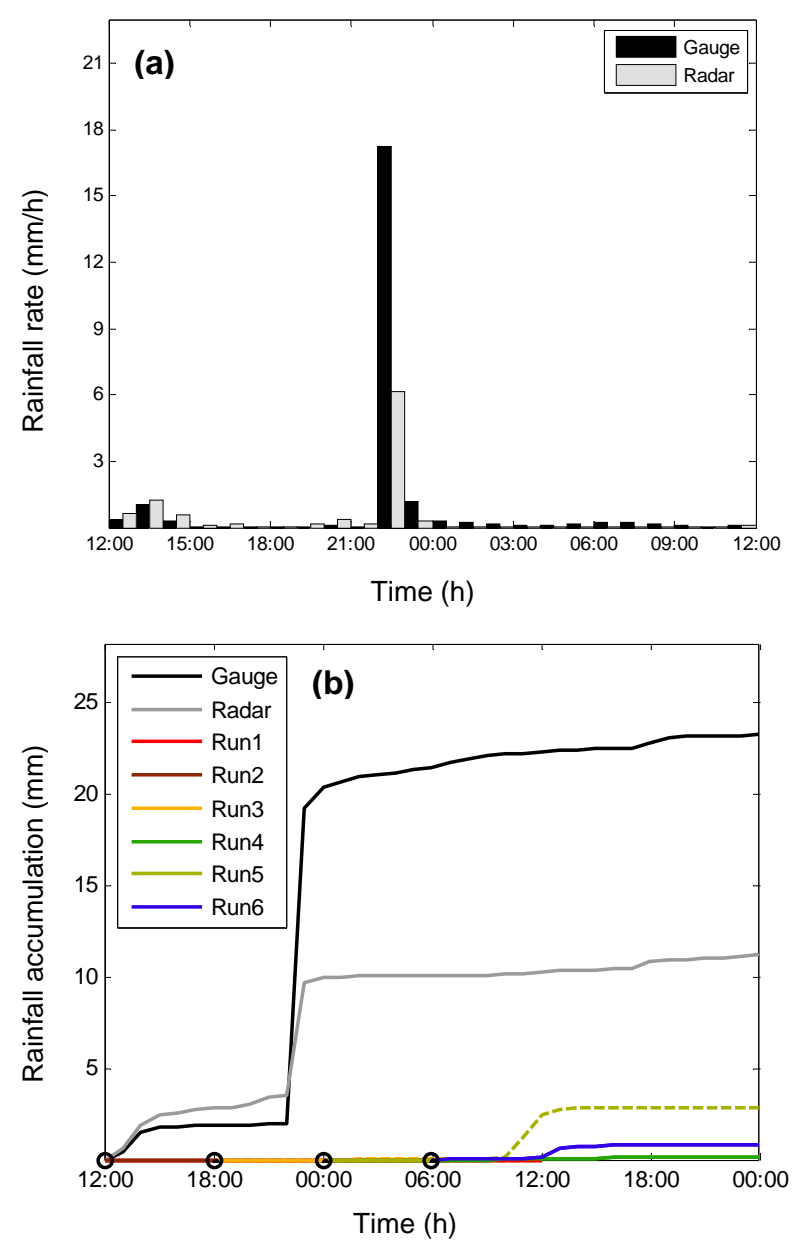

Fig. 7. Data-assimilation results for a highly convective storm: (a) radar and rain gauge observations for the $24 \mathrm{~h}$ duration ( $3 \mathrm{Au}-$ gust 1994 at 12:00-4 August 1994 at 12:00); (b) rainfall cumulative curves after assimilating both radar reflectivity and NCAR surface and upper-air observations ( $24 \mathrm{~h}$ duration $+12 \mathrm{~h}$ ).

consistent with the gauge and radar observations. The storm process is so short that the assimilated observations at a time interval of $6 \mathrm{~h}$ cannot provide sufficient information to trigger storm process in the WRF model. A heavy convective storm may develop very quickly without preceding precipitation being easily detected in the surrounding regions (Sokol, 2009). A shortened assimilation time interval together with data containing information of the cloud development (e.g. the satellite data) that precedes the formation of precipitation may help in this case to capture the evolution of the highly convective storm.

However, it should be noted that with the decrease of the assimilation time interval, the added information will not necessarily make the assimilation more effective (e.g. the information will become redundant with a very small interval). Therefore, the selection of an appropriate assimilation time interval remains an interesting issue that deserves more 
attention in future studies. Besides the time interval issue, in this study only data from the lowest scan elevation $\left(0.5^{\circ}\right)$ of the Wardon Hill radar are used. Actually in the 3D-Var system, data from different scan elevations can be assimilated in the meanwhile. Other scan elevations $\left(1.0^{\circ}, 1.5^{\circ}, 2.5^{\circ}\right)$ of the Wardon Hill radar that are available in the $5 \mathrm{~km}$ Cartesian grids are also worth trying. Further, comparison on the assimilation results of the $2 \mathrm{~km}$ and $5 \mathrm{~km}$ radar data could be made in order to investigate the appropriate horizontal resolution of the assimilated observations that well matches the resolutions of the nested domains. The involvement of the radial velocity together with the reflectivity might also help improve the assimilation results of the forecasted rainfall. With all the above investigated, the assimilation of radar data is expected to be comparable to or even more efficient than the assimilation of traditional meteorological observations. Finally, it should be emphasised that in this study the simplest configurations of 3D-Var data assimilation is adopted, i.e. by using the default background error covariance CV3 and assuming zero error of the radar reflectivity data. The performance of the data-assimilation system largely depends on the plausibility of the background and observation error covariances. However, the estimation of the error covariances has always been a problem due to the unavailability of the true state of the atmosphere. The use of the background-errorgenerating facility "GEN_BE" in the 3D-Var system might help more appropriately define the background error, and additional runs should be carried out to check the sensitivity of the results to the uncertainty in the background and observation error before the most plausible ones could be ascertained.

\section{Conclusions}

This study investigates the potential of assimilating radar reflectivity data in improving the NWP rainfall forecasts with respect to the cumulative quantities and temporal variations, which have direct impact on rainfall-runoff transformation in hydrological applications. The latest-generation mesoscale NWP model, WRF, is used in tandem with the 3D-Var dataassimilation technique to carry out the rainfall forecasting experiments for a $24 \mathrm{~h}$ storm event in a catchment with a drainage area of $135.2 \mathrm{~km}^{2}$. Radar reflectivity data from a $\mathrm{C}$-band weather radar is assimilated into the WRF model in their original quality, and also in a improved version by applying a real-time correction ratio developed according to the rain gauge observations. Besides the radar reflectivity, traditional meteorological data taken from the NCAR global data archive containing the surface and upper-air measurements of pressure, temperature, humidity and wind speed are also assimilated as a benchmark of the radar data assimilation. It is found in this study that the effect of assimilating either the original or the corrected radar reflectivity is not as good as the NCAR observations. Obvious improvement can be observed regarding both the rainfall cumulative curve and the $24 \mathrm{~h}$ rainfall total after assimilating the NCAR observations; however for radar data assimilation, although there is some improvement after the radar data are corrected by the realtime correction ratio, the improvements in both of the two cases are negligible compared with the assimilation of the traditional meteorological observations. This might be due to the inefficiency of the radar data utilisation in this study. To better use the radar data, reflectivity from different scan elevations should be assimilated together at an appropriate horizontal resolution. Decreasing the data-assimilation time interval can involve more observational information which may assist in capturing the development of short-duration storms. For weather radars with Doppler capacity, the assimilation of reflectivity together with radial velocity may also help to further improve the rainfall forecasts from the NWP model.

In order to fully investigate the potential of radar data assimilation, the original and corrected radar reflectivity data are assimilated respectively in combination with the NCAR surface and upper-air observations. The results of assimilating both the two types of observations (i.e. the radar reflectivity and the traditional meteorological data) are found to generate the best rainfall improvement compared with assimilating either one type of data. The effect of assimilating NCAR observations can be further improved by the involvement of the radar reflectivity. This is because of the good ability of the weather radar in estimating the rainfall occurrences and their temporal tendencies in spite of the underestimated rainfall quantities. However, for the overall improvement of the rainfall forecasts, the contribution made by the corrected radar data is less significant than the original radar data. Regarding this and the unobvious improvement made by the corrected data when the radar reflectivity is assimilated alone, it is concluded that the radar correction method adopted in this study is not mature enough. Limitations of the radar correction ratio are fully discussed, and a more comprehensive approach for direct adjustment of the radar reflectivity data considering not only the mean-field bias but also the range-dependent error and the orographic enhancement is to be found.

It should be mentioned that the conclusions made in this study are subject to the specific parameterisation schemes. Different parameterisation schemes may lead to different rainfall forecasting results of the WRF model after data assimilation. However, as aforementioned, it is difficult to set in advance the most appropriate parameterisations for future climatic events. Therefore, the most widely used parameterisations are adopted in this study. Further research is needed with different types of parameterisation schemes and various storm events so that the assimilation of radar data can be fully investigated and more general patterns can be found to better improve the effectiveness of radar data assimilation and the accuracy of NWP rainfall forecasts. Besides the parameterisation schemes, a plausible acquisition of the background error covariance and the observation error of the radar 
reflectivity should be taken into consideration during the procedure of data assimilation. Finally, it is noteworthy that in this study only the improvement of the catchment areal rainfall is examined in time. For larger catchments where the use of the distributed hydrological model is necessary, the spatial accuracy of the rainfall forecasts after data assimilation is also worth investigating. However, the increase of the spatial resolution and the domain size of the NWP model will result in a remarkable increase of the modelling time, which is not realistic in operational forecasting. In this study, the relatively "coarse" resolution and the limited size of the innermost domain are designed to save the downscaling and data-assimilation time in the three nested domains. To obtain more reliable NWP rainfall forecasts with higher horizontal resolutions, the time issue remains an unsolved problem which deserves more attentions in further studies. Optimised domain setting together with more efficient data-assimilation techniques may be able to help.

Acknowledgements. The authors thank the editor and the reviewers for their insightful comments and valuable suggestions in improving the quality of the paper.

Edited by: N. Verhoest

\section{References}

Anagnostou, E. N., Krajewski, W. F., Seo, D. J., and Johnson, E. R.: Mean-field radar rainfall bias studies for WSR-88D, J. Hydrol. Eng.-ASCE, 3, 149-159, 1998.

Austin, G. L., Bellon, A., Dionne, P., and Roch, M.: On the interaction between radar and satellite image nowcasting systems and mesoscale numerical models, in: Proceedings of Symposium on Mesoscale Analysis and Forecasting, 225-228, Vancouver, Canada, 1987.

Bader, M. J. and Roach, W. T.: Orographic rainfall in warm sectors of depressions, Q. J. Roy. Meteorol. Soc., 103, 269-280, 1977.

Barker, D. M., Huang, W., Guo, Y. R., Bourgeois, A., and Xiao, Q. N.: A three-dimensional variational data assimilation system for MM5: implementation and initial results, Mon. Weather Rev., 132, 897-914, 2004.

Bell, V. A. and Moore, R. J.: Short period forecasting of catchmentscale precipitation. Part II: a water-balance storm model for short-term rainfall and flood forecasting, Hydrol. Earth Syst. Sci., 4, 635-651, doi:10.5194/hess-4-635-2000, 2000a.

Bell, V. A. and Moore, R. J.: The sensitivity of catchment runoff models to rainfall data at different spatial scales, Hydrol. Earth Syst. Sci., 4, 653-667, doi:10.5194/hess-4-653-2000, 2000 b.

Berenguer, M. and Zawadzki, I.: A study of the error covariance matrix of radar rainfall estimates in stratiform rain, Weather Forecast., 23, 1085-1101, 2008.

Berenguer, M. and Zawadzki, I.: A study of the error covariance matrix of radar rainfall estimates in stratiform rain, Part II: scale dependence, Weather Forecast., 24, 800-811, 2009.

Borga, M.: Accuracy of radar rainfall estimates for streamflow simulation, J. Hydrol., 267, 26-39, 2002.
Borga, M., Tonelli, F., Moore, R. J., and Andrieu, H.: Long-term assessment of bias adjustment in radar rainfall estimation, Water Resour. Res., 38, 1226, doi:10.1029/2001WR000555, 2002.

Brown, R., Sargent, G. P., and Blackall, R. M.: Range and orographic corrections for use in real-time radar data analysis, in: Hydrological Applications of Weather Radar, edited by: Cluckie, I. D. and Collier, C. G., 219-228, Ellis Horwood, Chichester, England, 1991.

Browning, K. A., Pardoe, C. W., and Hill, F. F.: The nature of orographic rain at wintertime cold fronts, Q. J. Roy. Meteorol. Soc., 101, 333-352, 1975.

Chang, H. I., Kumar, A., Niyogi, D., Mohanty, U. C., Chen, F., and Dudhia, J.: The role of land surface processes on the mesoscale simulation of the July 26, 2005 heavy rain event over Mumbai, India, Global Planet. Change, 67, 87-103, 2009.

Chen, C. S., Lin, Y. L., Peng, W. C., and Liu, C. L.: Investigation of a heavy rainfall event over southwestern Taiwan associated with a subsynoptic cyclone during the 2003 Mei-Yu season, Atmos. Res., 95, 235-254, 2010.

Clark, C.: Floods at Bruton past, present and future, Charldon Publications, Bruton, UK, 1996.

Collier, C. G.: The height of the freezing level during rainfall over the British Isles, Meteorol. Mag., 105, 381-392, 1976.

Daley, R.: Atmospheric Data Analysis, Cambridge University Press, Cambridge, UK, 1991.

Dixon, M. and Wiener, G.: TITAN: thunderstorm identification, tracking, analysis and nowcasting-a radar-based methodology, J. Atmos. Ocean. Tech., 10, 785-797, 1993.

Dixon, M., Li, Z., Lean, H., Roberts, N., and Ballard, S.: Impact of data assimilation on forecasting convection over the United Kingdom using a high-resolution version of the Met Office Unified Model, Mon. Weather Rev., 137, 1562-1584, 2009.

Dudhia, J.: Numerical study of convection observed during the winter monsoon experiment using a mesoscale two-dimensional model, J. Atmos. Sci., 46, 3077-3107, 1989.

Ebert, E. E., Wilson, L. J., Brown, B. G., Nurmi, P., Brooks, H. E., Bally, J., and Jaeneke, M.: Verification of nowcasts from the WWRP Sydney 2000 Forecast Demonstration Project, Weather Forecast, 19, 73-96, 2004.

Eden, P.: Weather Log, Weather, 54, Royal Meteorological Society, available at: http://onlinelibrary.wiley.com/journal/10.1002/ (ISSN)1477-8696/issues (last access: 31 July 2013), 1999.

Ferraris, L., Rudari, R., and Siccardi, F.: The Uncertainty in the Prediction of Flash Floods in the Northern Mediterranean Environment, J. Hydrometeorol., 3, 714-727, 2002.

Germann, U., Galli, G., Boscacci, M., and Bolliger, M.: Radar precipitation measurement in a mountainous region, Q. J. Roy. Meteorol. Soc., 132, 1669-1692, doi:10.1256/qj.05.190, 2006 a.

Germann, U., Zawadzki, I., and Turner, B.: Predictability of Precipitation from Continental Radar Images. Part IV: Limits to Prediction, J. Atmos. Sci., 63, 2092-2108, doi:10.1175/JAS3735.1, 2006 b.

Germann, U., Berenguer, M., Sempere-Torres, D., and Zappa, M.: REAL - Ensemble radar precipitation estimation for hydrology in a mountainous region, Q. J. Roy. Meteorol. Soc., 135, 445456, doi:10.1002/qj.375, 2009.

Han, D., Cluckie, I. D., Griffith, R. J., and Austin, G.: Using weather radars to measure rainfall in urban catchments, Jouran of Urban Techonolgy, 5, 85-102, 2000. 
Hitschfeld, W. and Bordan, J.: Error inherent in the radar measurement of rainfall at attenuating wavelengths, J. Meteorol., 11, 5867, 1954.

Hong, S. Y. and Lee, J. W.: Assessment of the WRF model in reproducing a flash-flood heavy rainfall event over Korea, Atmos. Res., 93, 818-831, 2009.

Hong, S. Y., Dudhia, J., and Chen, S. H.: A revised approach to ice microphysical processes for the bulk parameterization of clouds and precipitation, Mon. Weather Rev., 132, 103-120, 2004.

Hong, S. Y., Noh, Y., and Dudhia, J.: A new vertical diffusion package with an explicit treatment of entrainment processes, Mon. Weather Rev., 134, 2318-2341, 2006.

Ide, K., Courtier, P., Ghil, M., and Lorenc, A. C.: Unified notation for data assimilation: Operational, sequential and variational, J. Meteorol. Soc. Jpn., 75, 181-189, 1997.

Joss, J. and Waldvogel, A.: Precipitation measurement and hydrology, in: Radar in Meteorology: Battan Memorial and 40th Anniversary Radar Meteorology Conference, edited by: Atlas, D., American Meteorological Society, Boston, USA, 577-606, 1990.

Kain, J. S.: The Kain-Fritsch convective parameterization: An update, J. Appl. Meteorol., 43, 170-181, 2004.

Kitchen, M. and Jackson, P. M.:, Weather radar performance at long range - Simulated and observed, J. Appl. Meteorol., 32, 975985, 1993.

Kitchen, M., Brown, R., and Davies, A. G.:, Real-time correction of weather radar data for the effects of bright band, range and orographic growth in widespread precipitation, Q. J. Roy. Meteorol. Soc., 120, 1231-1254, 1994.

Lorenc, A. C.: Analysis methods for numerical weather prediction, Q. J. Roy. Meteorol. Soc., 112, 1177-1194, 1986.

Liu, J., Bray, M., and Han, D.: Sensitivity of the Weather Research and Forecasting (WRF) model to downscaling ratios and storm types in rainfall simulation, Hydrol. Process., 26, 3012-3031, doi:10.1002/hyp.8247, 2012a.

Liu, J., Bray, M., and Han, D.: Exploring the effect of data assimilation by WRF-3DVar for numerical rainfall prediction with different types of storm events, Hydrol. Process., online first, doi:10.1002/hyp.9488, 2012b.

Macpherson, B.: Operational experience with assimilation of rainfall data in the Met Office Mesoscale model, Meteorol. Atmos. Phys., 76, 3-8, 2001.

Mecklenburg, S., Joss, J., and Schmid, W.: Improving the nowcasting of precipitation in an Alpine region with an enhanced radar echo tracking algorithm, J. Hydrol., 239, 46-68, 2000.

Mecklenburg, S., Jurczyk, A., Sturtz, J., and Osrótka, K.: Quantitative precipitation forecasts (QPF) based on radar data for hydrological models, COST Action 717: Use of radar observations in hydrological and NWP models, available at: http://www. smhi.se/hfa_coord/cost717/doc/WDF_01_200203_2.pdf (last access: 31 July 2013), 2002.

Mlawer, E. J., Taubman, S. J., Brown, P. D., Iacono, M. J., and Clough, S. A.: Radiative transfer for inhomogeneous atmospheres: RRTM, a validated correlated-k model for the longwave, J. Geogr. Res., 102, 16663-16682, 1997.

Moore, R. J., Jones, D. A., Cox, D. R., and Isham, V. S.: Design of the HYREX raingauge network, Hydrol. Earth Syst. Sci., 4, 521-530, doi:10.5194/hess-4-521-2000, 2000.

Monin, A. S. and Obukhov, A. M.: Basic laws of turbulent mixing in the ground layer of the atmosphere, Transactions of the Geo- physical Institute, 151, 163-187, 1954.

Parrish, D. F. and Derber, J. C.: The National Meteorological Center's spectral statistical-interpolation analysis system, Mon. Weather Rev., 120, 1747-1763, 1992.

Seo, D. J., Breidenbach, J. P., and Johnson, E. R.: Real-time estimation of mean-field bias in radar rainfall data, J. Hydrol., 223, 131-147, 1999.

Shem, W. and Shepherd, M.: On the impact of urbanization on summertime thunderstorms in Atlanta: two numerical model case studies, Atmos. Res., 92, 172-189, 2009.

Skamarock, W. C., Klemp, J. B., Dudhia, J., Gill, D. O., Barker, D. M., Duda, M. G., Huang, X. Y., Wang, W., and Powers, J. G.: A Description of the Advanced Research WRF Version 3, NCAR Technical Note, NCAR/TN-475+STR, 2008.

Sokol, Z.: Effects of an assimilation of radar and satellite data on a very short range forecast of heavy convective rainfalls, Atmos. Res., 93, 188-206, 2009.

Sokol, Z.: Assimilation of extrapolated radar reflectivity into a NWP model and its impact on a precipitation forecast at high resolution, Atmos. Res., 100, 201-212, 2010.

Sokol, Z. and Pešice, P.: Comparing nowcastings of three severe convective events by statistical and NWP models, Atmos. Res., 93, 397-407, 2009.

Sokol, Z. and Rezacova, D.: Assimilation of radar reflectivity into the LMCOSMO model with a high horizontal resolution, Meteorol. Appl., 13, 317-330, 2006.

Stephan, K., Klink, S., and Schraff, C.: Assimilation of radar derived rain rates into the convective scale model COSMO-DE at DWD, Q. J. Roy. Meteorol. Soc., 134, 1315-1326, 2008.

Sun, J.: Convective-scale assimilation of radar data: progress and challenges, Q. J. Roy. Meteorol. Soc., 131, 3439-3463, 2005.

Sun, J. and Crook, N. A.: Dynamical and microphysical retrieval from Doppler radar observations using a cloud model and its adjoint, Part I: Model development and simulated data experiments, J. Atmos. Sci., 54, 1642-1661, 1997.

Sun, J. and Crook, N. A.: Dynamical and microphysical retrieval from Doppler radar observations using a cloud model and its adjoint. Part II: Retrieval experiments of an observed Florida convective storm, J. Atmos. Sci., 55, 835-852, 1998.

Tong, M. and Xue, M.: Ensemble Kalman filter assimilation of Doppler radar data with a compressible nonhydrostatic model: OSS experiments, Mon. Weather Rev., 133, 1789-1807, 2005.

Wakimoto, R. M., Murphey, H. V., and Fovell, R. G.: Mantle echoes associated with deep convection: Observations and numerical simulations, Mon. Weather Rev., 132, 1701-1720, 2004.

Wang, H., Sun, J., Fan, S., and Huang, X. Y.: Indirect assimilation of radar reflectivity with WRF 3D-Var and its impact on prediction of four summertime convective events, J. Appl. Meteorol. Clim., 52, 889-902, 2013.

Wheater, H. S., Isham, V. S., Cox, D. R., Chandler, R. E., Kakou, A., Northrop, P. J., Oh, L., Onof, C., and Rodriguez-Iturbe, I.: Spatial-temporal rainfall fields: modelling and statistical aspects, Hydrol. Earth Syst. Sci., 4, 581-601, doi:10.5194/hess-4-5812000, 2000.

Wood, S. J., Jones, D. A., and Moore, R. J.: Accuracy of rainfall measurement for scales of hydrological interest, Hydrol. Earth Syst. Sci., 4, 531-543, doi:10.5194/hess-4-531-2000, 2000.

Xiao, Q. and Sun, J.: Multiple radar data assimilation and shortrange Quantitative Precipitation Forecasting of a squall line ob- 
served during IHOP 2002, Mon. Weather Rev., 135, 3381-3404, 2007.

Xiao, Q., Kuo, Y., Sun, J., Lee, W., Lim, E., Guo, Y., and Barker, D. M.: Assimilation of Doppler radar observations with a regional 3D-VAR system: impact of Doppler velocities on forecasts of a heavy rainfall case, J. Appl. Meteorol., 44, 768-788, 2005.

Xiao, Q., Kuo, Y., Sun, J., Lee, W., Barker, D. M., and Lim, E.: An approach of radar reflectivity data assimilation and its assessment with the inland QPF of Typhoon Rusa (2002) at landfall, J. Appl. Meteorol. Clim., 46, 14-22, 2007.
Xiu, A. and Pleim, J. E.: Development of a Land Surface Model, Part I: Application in a Mesoscale Meteorological Model, J. Appl. Meteorol., 40, 192-209, 2001. 